\title{
Ozone seasonality above the tropical tropopause: reconciling the Eulerian and Lagrangian perspectives of transport processes
}

\author{
M. Abalos ${ }^{1}$, F. Ploeger ${ }^{2}$, P. Konopka ${ }^{2}$, W. J. Randel ${ }^{3}$, and E. Serrano ${ }^{1}$ \\ ${ }^{1}$ Universidad Complutense de Madrid, Madrid, Spain \\ ${ }^{2}$ Institute of Energy and Climate Research: Stratosphere (IEK-7), Forschungszentrum Jülich, Jülich, Germany \\ ${ }^{3}$ National Center for Atmospheric Research, Boulder, Colorado, USA
}

Correspondence to: M. Abalos (mabalosa@fis.ucm.es)

Received: 4 June 2013 - Published in Atmos. Chem. Phys. Discuss.: 22 July 2013

Revised: 7 October 2013 - Accepted: 14 October 2013 - Published: 6 November 2013

\begin{abstract}
We aim to reconcile the recently published, apparently contrasting results regarding the relative importance of tropical upwelling versus horizontal transport for the seasonality of ozone above the tropical tropopause. Different analysis methods in the literature (Lagrangian versus Eulerian, and isentropic versus pressure vertical coordinates) yield different perspectives of ozone transport, and the results must be carefully compared in equivalent terms to avoid misinterpretation. By examining the Lagrangian calculations in the Eulerian formulation, we show here that the results are in fact consistent with each other and with a common understanding of the ozone transport processes near and above the tropical tropopause.

We further emphasize that the complementary approaches are suited for answering two different scientific questions: (1) what drives the observed seasonal cycle in ozone at a particular level above the tropical tropopause? and (2) how important is horizontal transport from mid-latitudes for ozone concentrations in the tropical lower stratosphere? Regarding the first question, the analysis of the transformed Eulerian mean (TEM) ozone budget shows that the annual cycle in tropical upwelling is the main forcing of the ozone seasonality at altitudes with large vertical gradients in the tropical lower stratosphere. To answer the second question a Lagrangian framework must be used, and the results show that a large fraction $(\sim 50 \%)$ of the ozone molecules ascending through the tropical lower stratosphere is of extra-tropical origin and has been in-mixed from mid-latitudes.
\end{abstract}

\section{Introduction}

Ozone concentrations in the lower tropical stratosphere are determined by photochemical production and by transport processes (e.g., Avallone and Prather, 1996). Photochemical production and horizontal transport of ozone-rich midlatitude air into the tropics (denoted in-mixing in the following) increase ozone mixing ratios above the tropical tropopause. The vertical upward motion in the tropical lower stratosphere carries air masses from below, with lower ozone concentrations, with seasonally varying strength. Upwelling effectively acts to decrease ozone in the tropical lower stratosphere, where the steepest relative vertical ozone gradients are found, and is balanced in the time mean by photochemical production and in-mixing.

Observations of ozone reveal a large seasonal cycle with a characteristic narrow vertical structure just above the tropical tropopause. Randel et al. (2007) highlighted this behavior and proposed that it was forced by the seasonality in tropical upwelling acting on the strong ozone background vertical gradients. Recently, Abalos et al. (2012) computed the seasonality of the different terms in the transformed Eulerian mean (TEM) transport equation using satellite observations of ozone and reanalysis meteorological fields, and found that the seasonality in ozone mainly followed the seasonality of vertical advection by upwelling at levels with large vertical gradients. Hence, these works concluded that vertical advection within the tropics is the main forcing of the ozone seasonality at a fixed altitude level in the TEM framework.

On the other hand, Konopka et al. (2009) examined the origin of the ozone annual cycle using a conceptual 
one-dimensional tropical trace gas model, and proposed that quasi-horizontal transport played a primary role in causing the ozone seasonality. Furthermore, Konopka et al. (2010) observed a clear summer maximum in isentropic ozone transport from the northern mid-latitudes into the tropics (inmixing) associated with the Asian monsoon upper level circulation, in global model simulations with the Chemical Lagrangian Model of the Stratosphere (ClaMS; McKenna et al., 2002). Using three-dimensional back trajectories and a one-dimensional conceptual model, which explicitly included in-mixing from mid-latitudes, Ploeger et al. (2012) further showed that the ozone annual cycle above the tropical tropopause entirely disappeared if in-mixing was inhibited. Consequently, from a Lagrangian perspective following air parcel trajectories, in-mixing of mid-latitude air into the tropics appeared essential for explaining tropical ozone mixing ratios, and particularly the ozone summer maximum.

These results evidence a current lack of understanding regarding the origin of the ozone seasonality in the tropical tropopause layer (TTL) (e.g., Fueglistaler et al., 2009) and tropical lower stratosphere. More specifically, there seems to be a contradiction between the Eulerian results of Randel et al. (2007) and Abalos et al. (2012), who conclude that tropical upwelling is the main driver of the annual cycle in ozone above the tropical tropopause, and the Lagrangian results of Konopka et al. (2009, 2010) and Ploeger et al. (2012), who find that in-mixing is essential for the seasonality. This controversy in the recent literature regarding tropical ozone concentrations is not found for other species (e.g., carbon monoxide, water vapor, nitrous oxide) because the effect of in-mixing is weaker due to the relatively smaller meridional gradients between tropics and extra-tropics in these tracers (Ploeger et al., 2012).

To some extent, the conflict arises from the different vertical coordinates used in the analyses, i.e., pressure versus potential temperature (isentropic) coordinates. As noted by Konopka et al. (2009), the amplitude of the annual cycle in ozone is notably reduced (by $\sim 60 \%$ ) on isentropic levels compared to altitude (or pressure). This is due to the large seasonality in the altitude of the isentropes above the tropical tropopause (linked to temperature changes associated with the seasonality in upwelling). Very recently, Abalos et al. (2013) explicitly compared the differences in the ozone budgets between pressure and isentropic coordinates. Their results show that, on isentropic levels above the tropopause (corresponding to mean log-pressure altitudes with large annual cycles in temperature and ozone) the net tendency is small compared to the other terms in the ozone budget. Thus, despite the overall similarity of the balances in both coordinate systems, on isentropes the reduced ozone seasonality does not follow the larger annual cycle in diabatic advection. However, this fundamental difference only partially explains the apparent contradiction between the abovementioned works.
In this paper, we demonstrate that the remaining conflict can be reconciled by taking account of the differences between the Eulerian versus Lagrangian perspectives. The Eulerian view separates vertical and horizontal components of transport at each level, such that air parcels are identified as in-mixed only if they are transported horizontally into the tropics at that particular level. The Lagrangian method integrates changes in ozone concentration along each parcel trajectory, so that air parcels are considered in-mixed if they are transported horizontally into the tropics either at that level or at lower levels. Hence, air masses that are in-mixed by the Asian monsoon anticyclone at a given altitude and then vertically advected within the tropics by upwelling will be considered as transported vertically across an upper level in the Eulerian calculations, but represent horizontal transport in the Lagrangian analysis. Abalos et al. (2013) examined the ozone budget using output from a chemistry-climate model, which explicitly resolved all terms in the TEM equation, including eddy transport terms. Their results showed a detailed vertical structure in ozone transport seasonality near the tropical tropopause, with isentropic transport associated with the Asian monsoon dominating around tropopause level and tropical upwelling driving ozone seasonality at higher altitudes ( $\sim 2 \mathrm{~km}$ above). In the present work we bring together the Eulerian and the Lagrangian analyses to demonstrate that both views are consistent, and provide a complementary understanding of ozone transport near the tropical tropopause.

The used method and models are described in Sect. 2. Section 3 presents the results, concerning the seasonality of ozone in the tropical lower stratosphere from the Eulerian and Lagrangian perspectives. In the following Sect. 4 we discuss these results and implications.

\section{Model data and method}

In order to compare the Lagrangian and Eulerian frameworks, we contrast results from the WACCM (Whole Atmosphere Community Climate Model, Garcia et al., 2007) chemistry climate model, as used by Abalos et al. (2013), with results from the conceptual Lagrangian onedimensional tropical tracer model (termed "1-D model" in the following), used by Ploeger et al. (2012). The output of the Lagrangian 1-D model will be transformed into Eulerian information, in order to compare equivalent terms.

The conceptual 1-D model for tropical ozone mixing ratio is based on a tropical mean description:

$\frac{d \chi}{\mathrm{d} t}=P-\alpha_{\mathrm{N}}\left(\chi-\chi_{\mathrm{N}}\right)-\alpha_{\mathrm{S}}\left(\chi-\chi_{\mathrm{S}}\right)$.

Here, $\chi$ represents a tropical $\left(20^{\circ} \mathrm{S}-20^{\circ} \mathrm{N}\right)$ mean, $\frac{d}{\mathrm{~d} t}$ is the one-dimensional material derivative following the mean upward motion, $\chi_{\mathrm{N}}$ and $\chi_{\mathrm{S}}$ are the mean Northern Hemisphere $(\mathrm{NH})$ and Southern Hemisphere $(\mathrm{SH})$ mid-latitude annual mean mixing ratios, and $\alpha_{\mathrm{N}}$ and $\alpha_{\mathrm{S}}$ are the inverse 
in-mixing damping timescales for the $\mathrm{NH}$ and $\mathrm{SH}$, respectively. $P$ is the tropical mean photochemical ozone production rate, taken from the Lagrangian chemistry transport model ClaMS. Horizontal in-mixing (i.e., the sum of advective transport and eddy mixing) is represented as a relaxation against $\chi_{\mathrm{N}}$ and $\chi_{\mathrm{S}}$, which are taken from the 19912002 HALOE climatology of Grooß and Russell (2005). The in-mixing inverse damping timescales, $\alpha_{N}$ and $\alpha_{S}$, are diagnosed from CLaMS three-dimensional (3-D) back trajectories based on ERA-Interim reanalysis winds, as described in Ploeger et al. (2012). The tropical mean vertical upwelling velocity $\dot{\theta}=Q$ is taken from ERA-Interim, after correcting for the excessively rapid upward transport in the TTL region in this reanalysis by multiplying the heating rate $Q$ by 0.6 (for a more detailed discussion see Ploeger et al., 2012). Note that the in-mixing rates $\alpha_{\mathrm{N}}$ and $\alpha_{\mathrm{S}}$ depend on potential temperature and time and show an annual cycle with maximum during hemispheric summer (as shown in Ploeger et al., 2012, Fig. 5), while the mean extra-tropical mixing ratios used here, $\chi_{\mathrm{N}}$ and $\chi_{\mathrm{S}}$, are annual mean quantities depending only on potential temperature. The results obtained using time-varying (i.e., monthly mean) values for these concentrations are qualitatively similar (not shown).

Equation (1) is formulated in Lagrangian terms, and they state that the rate of change in the concentration of ozone in a given air parcel ascending in the tropics, given by the material derivative $(d \chi / \mathrm{d} t)$, is determined exclusively by the sources and sinks $(S)$ :

$$
\frac{d \chi}{\mathrm{d} t}=S
$$

with the source term $S=P-\alpha_{\mathrm{N}}\left(\chi-\chi_{\mathrm{N}}\right)-\alpha_{\mathrm{S}}\left(\chi-\chi_{\mathrm{S}}\right)$ (see Eq. 1). Ploeger et al. (2012) demonstrated that lateral inmixing from the extra-tropics must be included in the conceptual 1-D tropical-averaged model in order to obtain a realistic representation of both the mean tropical ozone profile and its seasonality. Consequently, the source term $S$ in this model comprises both photochemical production and lateral in-mixing from the extra-tropics.

From the Lagrangian point of view of Eq. (2) the observer follows the air parcel trajectory, as expressed by the material derivative. From the Eulerian point of view, on the contrary, the observer is fixed at a given location and perceives the flow passing by. In order to transform Eq. (2) into an Eulerian equation, the material derivative is expressed as a function of the local tendency plus the change due to the spatial displacement of the parcel: $\frac{d}{\mathrm{~d} t}=\frac{\partial}{\partial t}+\dot{\theta} \frac{\partial}{\partial \theta}(\theta$ is the only spatial coordinate in the tropical 1-D model). The ozone tendency at a fixed level can then be isolated in the Eulerian version of Eq. (2):

$$
\frac{\partial \chi}{\partial t}=-\dot{\theta} \frac{\partial \chi}{\partial \theta}+S
$$

While the Lagrangian transport equation (Eq. 2) is integrated along the parcel trajectory to give the ozone concentration of the parcel at a given position, $\chi(\theta(t))$, the Eulerian equation (Eq. 3), is integrated in time at a given position to yield the concentration at this level and time, $\chi(t, \theta)$. This subtle but fundamental difference is key for interpreting the results from different analyses and comparing them unambiguously.

Using $\frac{d}{\mathrm{~d} t}=\dot{\theta} \frac{d}{d \theta}$ (which is implied by $\dot{\theta} \equiv \frac{d \theta}{\mathrm{d} t}$ ), Eq. (1) can be re-written as:

$\frac{d \chi}{d \theta}=\frac{P}{\dot{\theta}}-\frac{\alpha_{\mathrm{N}}\left(\chi-\chi_{\mathrm{N}}\right)-\alpha_{\mathrm{S}}\left(\chi-\chi_{\mathrm{S}}\right)}{\dot{\theta}}$,

which explicitly shows the effect of tropical upwelling in the Lagrangian model. The inverse dependence on $\dot{\theta}$ of the change in ozone along the trajectory implies that slower ascent in summer results in longer transit times for photochemistry and in-mixing to increase ozone concentrations in the air parcel. We calculate the mean tropical ozone mixing ratio from the analytic solution of Eq. (2) (Eq. A1 in Ploeger et al., 2012), using an integration step of $0.5 \mathrm{~K}$ potential temperature. The ERA-Interim data used in the 1-D model has been interpolated to isentropic levels with $10 \mathrm{~K}$ vertical spacing between $360 \mathrm{~K}$ and $500 \mathrm{~K}$.

The 1-D-model results will be compared to results from the WACCM free-running simulation described in Abalos et al. (2013), in terms of the transformed Eulerian mean (TEM) tracer continuity equation for ozone concentration (Eq. 9.4.13 in Andrews et al., 1987), neglecting the small vertical eddy term for simplicity:

$$
\frac{\partial \bar{\chi}}{\partial t}=P-\bar{w}^{*} \frac{\partial \bar{\chi}}{\partial z}+\left[-\bar{v}^{*} \frac{\partial \bar{\chi}}{\partial y}+\frac{e^{z / H}}{\cos \varphi} \frac{\partial\left(M_{y} \cos \varphi\right)}{\partial y}\right] .
$$

Alternatively, the isentropic formulation is (Eq. 9.4.21 in Andrews et al., 1987):

$$
\frac{\partial \bar{\chi}}{\partial t}=P-\bar{Q}^{*} \frac{\partial \bar{\chi}}{\partial \theta}+\left\{-\bar{v}^{*} \frac{\partial \bar{\chi}}{\partial y}-\bar{\sigma}^{-1} \frac{\partial}{\partial y}\left(\overline{\left[(\sigma v)^{\prime} \chi^{\prime}\right]}\right)\right\}
$$

In Eq. (5) overbars indicate zonal mean quantities, $\left(\bar{v}^{*}, \bar{w}^{*}\right)$ are the meridional and vertical components of the residual circulation, while $\left(\bar{v}^{*}, \bar{Q}^{*}\right)$ in Eq. (6) are the isentropic meridional and cross-isentropic velocities weighted by the isentropic mass density $\sigma \equiv-1 / g \cdot(\partial p / \partial \theta) . \bar{\chi}$ is the zonal mean ozone mixing ratio, $P$ is the net ozone production rate, $\varphi$ is the latitude and $M_{y} \equiv-e^{-z / H}\left(\overline{v^{\prime} \chi^{\prime}}-\frac{\partial \bar{\chi}}{\partial z} \cdot \overline{v^{\prime} T^{\prime}} / S\right)$ is the horizontal component of eddy transport. The bracketed term on the right-hand side of each equation is the (horizontal or isentropic) in-mixing, which includes both horizontal eddy transport and advection. In particular, the in-mixing term (bracketed term) is equivalent to the term $-\alpha_{N}\left(\chi-\chi_{N}\right)-\alpha_{S}\left(\chi-\chi_{S}\right)$ in the 1-D model (Eq. 1). Further details on these equations can be found in Abalos et al. (2013). For our analysis of tropical mean ozone, Eqs. (5) and (6) are averaged over the tropics $\left(20^{\circ} \mathrm{S}-20^{\circ} \mathrm{N}\right)$ throughout this paper, and we compute monthly means to examine the seasonality of the different terms. We note here that in the 

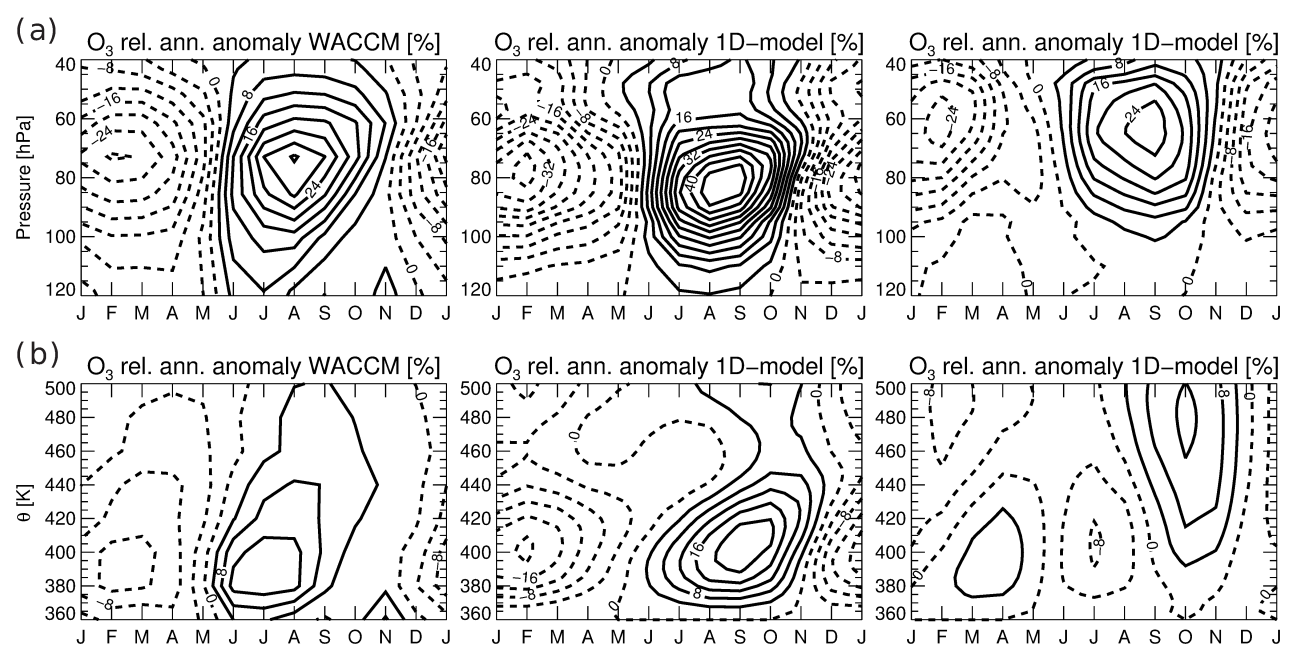

Fig. 1. Relative annual anomaly for tropical $\left(20^{\circ} \mathrm{S}-20^{\circ} \mathrm{N}\right)$ ozone on pressure levels (a) and on isentropes (b) [\%]. Percentages are relative to the annual mean concentrations. Results are shown from WACCM (left), from the 1-D model (middle) and from the 1-D model without including in-mixing (right). Solid (dashed) contours indicate positive (negative) values. Contour interval: $4 \%$.

WACCM free-running simulation, the tropical tropopause is approximately $1 \mathrm{~km}$ higher than observed. There is a corresponding vertical shift in ozone seasonality so that the maximum amplitude is found approximately $1 \mathrm{~km}$ above the level where it is observed by in situ measurements, as discussed in Abalos et al. (2013). The vertical resolution in this WACCM simulation is between 1.1 and $1.4 \mathrm{~km}$ in the upper troposphere and lower stratosphere (i.e., pressure levels around the tropical tropopause are $\sim 118,101,86,73$, and $62 \mathrm{hPa}$ ).

It is important to bear in mind that our aim is not to compare both models in detail, since they are radically different (a complex global chemistry-climate model versus a conceptual tropical 1-D model), and identical behavior should not be expected in the exact amplitude and timing or the precise levels involved in the ozone seasonality. Instead, our aim is to investigate if there is evidence for a common understanding of the transport processes that cause the ozone seasonality near the tropical tropopause, in spite of the very different nature of the models and the analyses.

\section{The annual cycle of tropical ozone}

Figure 1 shows the tropical mean ozone seasonality obtained with the Lagrangian 1-D model and WACCM. The results are shown on both pressure and isentropic levels, and the decrease in amplitude on isentropic compared to pressure coordinates is evident. Despite the very different nature of the models, the comparison shows similar overall characteristics. In particular, there is a broad maximum in summer centered near $\sim 80 \mathrm{hPa}(\sim 70 \mathrm{hPa}$ in WACCM $)$, and near the $400-420 \mathrm{~K}$ isentropes (380-400 K in WACCM).
Figure 1 also shows the results of the 1-D model if inmixing is inhibited (right column). On pressure levels, the amplitude of the ozone annual cycle is reduced by $\sim 50 \%$ and shifted to upper levels. On isentropes, the annual cycle almost completely disappears. This demonstrates that inmixing is essential for reproducing the observed ozone seasonality in the 1-D model. In particular, on isentropes almost the entire annual cycle of ozone can be attributed to in-mixing (with more ozone in-mixed during boreal summer than winter).

In the next sub-sections we address the question of whether the ozone seasonality in Fig. 1 is driven by the same forcings in both models.

\subsection{Eulerian view of Lagrangian results}

Figure 2 shows the mean seasonal cycle of the terms in the TEM continuity equation for ozone using results from WACCM (Eq. 5) averaged over $20^{\circ} \mathrm{S}-20^{\circ} \mathrm{N}$ and from the 1-D model after transforming the Lagrangian results to the Eulerian perspective, so that both are directly comparable. This is done by substituting the specific ozone sources in the 1-D model in Eq. (3):

$$
\frac{\partial \chi}{\partial t}=-\dot{\theta} \frac{\partial \chi}{\partial \theta}+P-\alpha_{\mathrm{N}}\left(\chi-\chi_{\mathrm{N}}\right)-\alpha_{\mathrm{S}}\left(\chi-\chi_{\mathrm{S}}\right)
$$

The monthly means are computed over the 2004-2009 period for WACCM and 2005-2006 for the Lagrangian 1-D model. The ozone budget is fairly similar between these two completely different models. The seasonality in the ozone tendency is largest at the upper levels, and it follows the seasonality in upwelling, the dominant term in both models. At lower altitudes $(86 \mathrm{hPa}$ in WACCM, $101 \mathrm{hPa}$ in the 1-D model), the seasonality in upwelling and in ozone is smaller, 

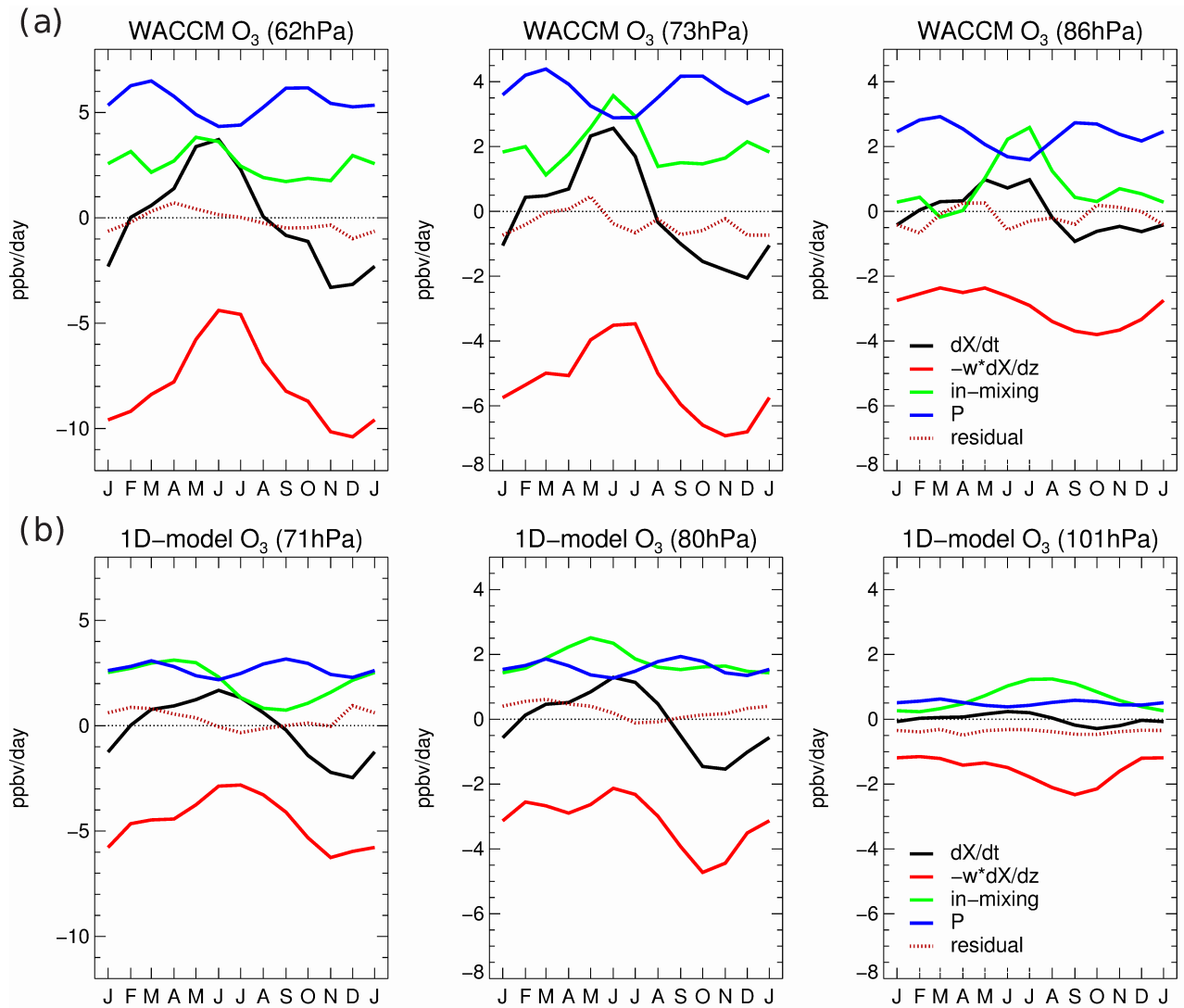

Fig. 2. Seasonal cycle of the various tendency terms in the TEM equation for mean tropical ozone concentration $\left(20^{\circ} \mathrm{S}-20^{\circ} \mathrm{N}\right)$ computed from WACCM (a), after Abalos et al. (2013), and from the 1-D Lagrangian model results (b) at different pressure levels (see text for details). Shown are the net tendency (black), the contributions due to vertical advection (red), horizontal transport (green), photochemical production (blue), and a residual term (red dashed). In order to account for the vertical shift of the tropopause altitude in WACCM, the balances are shown at slightly higher log-pressure altitudes than in the 1-D model (see text for details). Units: [ppbv day ${ }^{-1}$ ].

and the in-mixing term exhibits a boreal summer maximum in both models, which is smoother and more spread in time in the Lagrangian model than in WACCM. The similarity of the budgets in Fig. 2 demonstrates that the models are consistent, in that similar forcings act to generate the seasonality in ozone at the different levels. Furthermore, in the Lagrangian model the vertical advection term is the leading contribution to the ozone seasonality at levels with strong background gradients, when the results are examined from an Eulerian perspective.

\subsection{Vertical structure of in-mixing}

Figure 3 shows the seasonality of in-mixing, presented as its net effect on tropical ozone tendency (relative to the annual mean ozone mixing ratio), as a function of isentropic levels for both WACCM and the Lagrangian 1-D model. In WACCM, the net effect is computed by averaging the bracketed term in Eq. (6) over the tropical band $\left(20^{\circ} \mathrm{S}-20^{\circ} \mathrm{N}\right)$. Again, we note that the magnitude and exact levels are not expected to be comparable, and only broad characteristics should be considered. The seasonality of in-mixing shows a common feature in both models: there is strong in-mixing of ozone during the NH summer limited to isentropic levels below $\sim 420 \mathrm{~K}$, while at higher levels both models experience slightly more in-mixing in boreal winter-spring compared to summer-autumn.

In both models the strong maximum is clearly identified in the ozone in-mixing during boreal summer at levels around the tropical tropopause, which is associated with the monsoons (as discussed by Konopka et al. (2010) and Ploeger et al. (2012)). The vertical extension of this summer maximum is larger in WACCM, while in the 1-D model the maximum is broader in time. Notwithstanding these differences, both models show this maximum and a consistent transition to a smaller seasonality at higher altitudes, with somewhat larger in-mixing during winter and spring compared to summer and fall.

The overall similarity between the models in the vertical structure of the ozone in-mixing seasonality in Fig. 3 suggests an underlying common understanding of horizontal transport processes, as will be discussed in Sect. 4. 


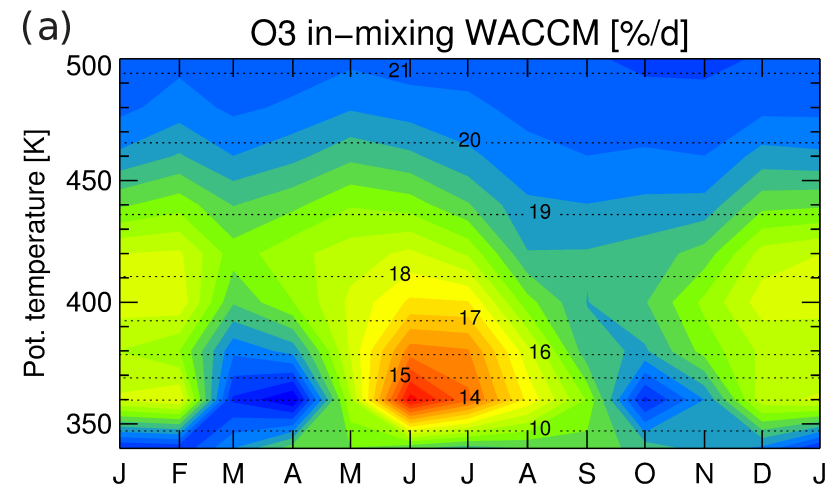

(b) O3 in-mixing 1D-model $[\% / d]$

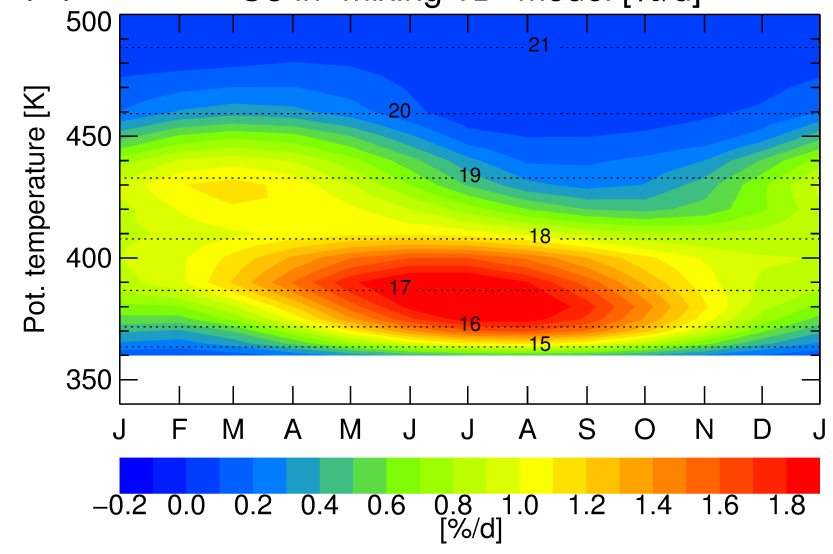

Fig. 3. Vertical structure of the seasonal cycle in in-mixing of ozone into the tropics $\left(20^{\circ} \mathrm{S}-20^{\circ} \mathrm{N}\right)$. Shown is the in-mixing contribution to the ozone tendency relative to the annual mean ozone concentration in $\left[\% \mathrm{day}^{-1}\right]$, from WACCM (a) and from the 1-D model (b). See text for details. Log-pressure annual mean altitudes for each model are indicated by the horizontal dotted lines and labeled in $\mathrm{km}$. Color bar range is -0.2 (blue) to 1.8 (red) $\left[\% \mathrm{day}^{-1}\right]$.

\subsection{Contribution of in-mixing to ozone concentrations}

From the Lagrangian point of view, air parcels ascending through the tropics during boreal summer may be enriched in ozone either by photochemical production within the tropics or by in-mixing of ozone-rich air from middle latitudes, as expressed by Eq. (4).

Figure 4a shows these contributions (i.e., the two terms on the right-hand side of Eq. 4) to the change in ozone concentration in an ascending tropical air parcel arriving at $500 \mathrm{~K}$ on 15 February from the 1-D model. This particular parcel in Fig. 4a ascended through the TTL during the previous summer (time along the trajectory is indicated by the encircled plus symbols), when in-mixing rates in the TTL were largest (see Fig. 3). In Fig. 4, in-mixing of middle latitude ozone (solid line) clearly dominates the increase in ozone along the trajectory at levels below $\sim 420 \mathrm{~K}$, and this contribution shows a sharp peak just above the tropical tropopause (around $390 \mathrm{~K}$ ). The rapid decrease in this contribution above

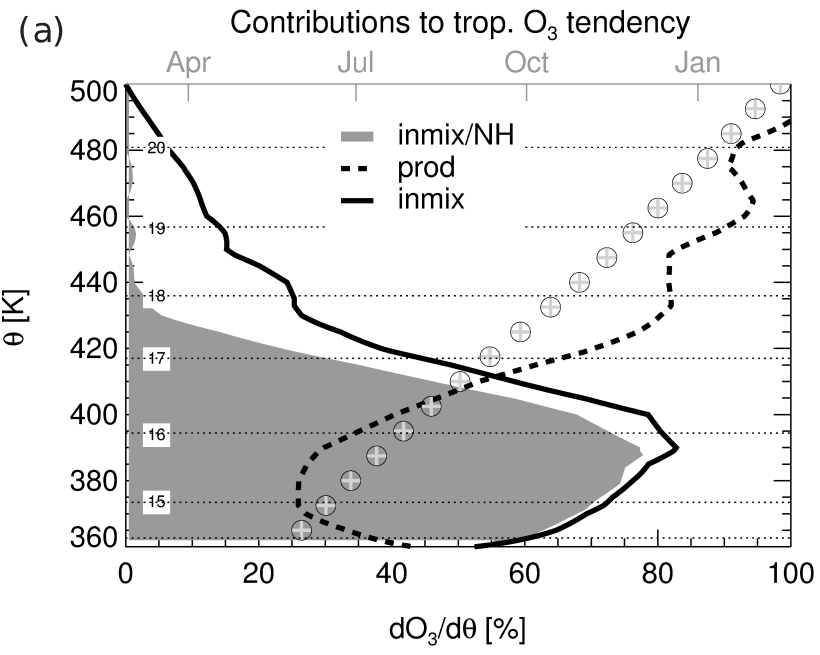

(b)

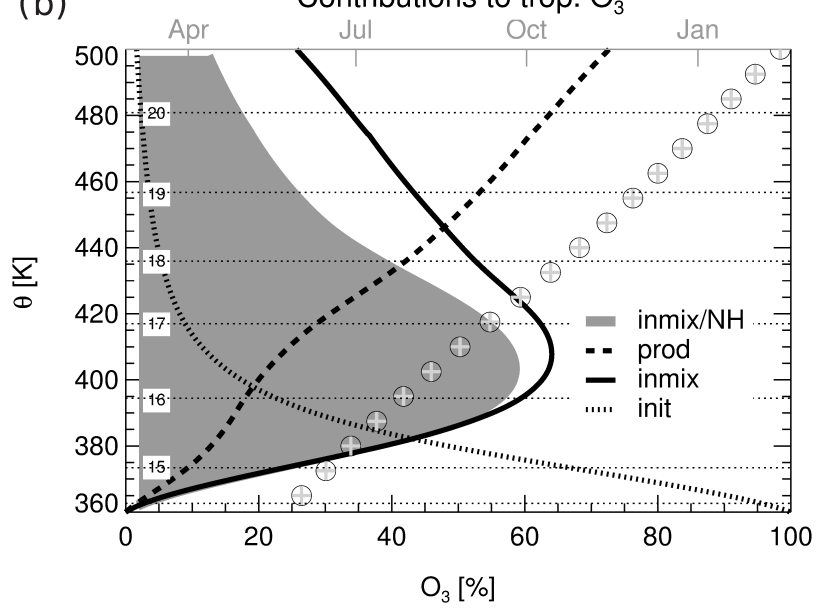

Fig. 4. (a) Relative contributions [\%] to the change in ozone (i.e., ozone tendency) along an ascending tropical trajectory in the 1-D model. The parcel reaches the level of $500 \mathrm{~K}$ on 15 February and hence ascends through the TTL during the previous summer (time along the parcel trajectory is indicated by the gray "+" symbols, with scale shown in the upper x-axis). The different lines show: photochemical production along the ascent (black dashed), total inmixing (black solid), in-mixing from the NH only (gray shading). The tendency terms are expressed as given on the right-hand side of Eq. (4), and shown relative to the total tendency at each level. (b) Same as (a), but for the contributions to mean tropical ozone. The dotted line labeled "init" shows the contribution of the initialization concentration in the 1-D model (i.e., SHADOZ ozone at $360 \mathrm{~K}$ ). This term is necessary for the lines in (b) to sum $100 \%$. Log-pressure annual mean altitudes are indicated by the horizontal dotted lines and labeled in $\mathrm{km}$.

$\sim 420 \mathrm{~K}$ is consistent with the vertical structure of in-mixing observed in Fig. 3. Figure 4a further shows that the main contribution to in-mixing originates in the $\mathrm{NH}$ (gray shading shows $\mathrm{NH}$ contribution to in-mixed ozone) and is related to the Asian monsoon. On the other hand, the increase in ozone due to photochemical production along the trajectory 
increases gradually with height (dashed line). Both contributions are comparable around $\sim 420 \mathrm{~K}$.

Although the relative contribution of in-mixing to the increase in ozone along the trajectory $(d \chi / d \theta)$ is largely reduced at higher levels, a significant fraction of the ozone above the TTL is of extra-tropical origin. This is illustrated in Fig. 4b, which shows the contributions to the net ozone mixing ratio of photochemistry and in-mixing integrated (from $360 \mathrm{~K}$ to each level above) along the same tropical trajectory discussed above. For instance, as the parcel crosses the $450 \mathrm{~K}$ isentrope, in-mixing contributes only about $15 \%$ to the increase in ozone (Fig. 4a). However, a large fraction (about $50 \%$ ) of tropical ozone at this level was originally located in mid-latitudes and has been in-mixed at lower levels (the remaining $50 \%$ of ozone molecules have been produced by photochemistry along the trajectory).

The Eulerian calculations do not provide this information on the origin of air parcels (or ozone molecules); it can only be obtained with the Lagrangian analysis, which integrates along the trajectories and hence preserves the memory of air parcels.

\section{Discussion}

There are two main reasons for the apparent discrepancy in the literature regarding the origin of the ozone seasonality in the TTL and lower tropical stratosphere. The first reason is that various analyses use different coordinate systems. On pressure coordinates there is a large seasonal cycle in ozone that peaks near the level of sharpest vertical gradients and follows the seasonality in upwelling. On isentropic coordinates the annual cycle is much reduced and is largest near the tropopause (and not at levels with larger vertical gradients), and completely disappears in the 1-D model if in-mixing is removed (Fig. 1). The effects of using either of these alternative coordinate systems on the ozone budget in the tropical lower stratosphere have been explored by Konopka et al. (2009) and Abalos et al. (2013). They showed that on isentropic coordinates the influence of upwelling on ozone is almost completely removed, and consequently the annual cycle in ozone is reduced due to the large annual cycle of the isentropes relative to pressure levels (induced by upwelling), which is almost in-phase with ozone.

The second reason for the apparent discrepancy regards the difference between the Lagrangian versus the Eulerian transport methodologies. Figure 2 proves that the Lagrangian analysis is consistent with the Eulerian results. On a fixed pressure level above the tropical tropopause (with large background gradients in ozone, e.g., $62 \mathrm{hPa}$ in WACCM and $71 \mathrm{hPa}$ in the 1-D model), the ozone tendency closely follows the vertical advection term in the zonal mean TEM tracer continuity equation and, in this sense, the seasonality of tropical mean ozone is forced by tropical upwelling in both models. However, in the same 1-D model the season- ality in ozone changes substantially if in-mixing is inhibited (50\% reduction on pressure levels, vanishing annual cycle on isentropes), implying that in-mixing makes a significant contribution to high ozone concentrations in boreal summer, and hence to the ozone seasonality. The key information to reconcile this apparent inconsistency is that substantial in-mixing of ozone molecules from the NH mid-latitudes caused by the Asian monsoon anticyclone during summer takes place in the TTL close to the tropopause. Above the TTL, in-mixing rapidly decreases with height, and the ozone seasonality follows the seasonality of vertical advection.

All these features are consistently observed in both models, and consequently there is no actual contradiction between the results of the different analyses. Choosing the Eulerian or the Lagrangian approach depends on the question that one is interested in answering. In particular, two relevant scientific questions are related to this issue: (1) what drives the large annual cycle above the tropical tropopause? and (2) where does the ozone that ascends within the tropical pipe come from? The first question regards the "forcing" of ozone seasonality and the second the "origin" of tropical ozone molecules. Here, the term "forcing" refers to the dominant term in the zonal mean ozone continuity equation at a particular level. In this sense, the TEM framework shows that the seasonality in tropical upwelling constitutes the main "forcing" of the annual cycle in ozone at levels with large vertical gradients. On the other hand, the term "origin" distinguishes between photochemical production within the tropics and in-mixing from mid-latitudes as sources for tropical ozone. In this sense, the Lagrangian approach is suited to understanding the "origin" of ozone molecules entering the tropical stratosphere and shows that, particularly during summer, a substantial amount of tropical ozone originates in middle and high latitudes.

We note that, strictly speaking, neither the Eulerian nor the Lagrangian methodology entirely separates the effects of tropical upwelling and of horizontal in-mixing on tropical ozone. In-mixing at levels of the TTL affects the ozone profile and gradient, and hence may impact the seasonality in the vertical advection term. Near the tropopause (below $\sim 80 \mathrm{hPa}$ ), the vertical gradient in ozone has a seasonal cycle that is almost opposite to the cycle in upwelling, such that the vertical advection term shows relatively little seasonality at this level (Fig. 2). At higher levels, the stronger background gradients are nearly constant and vertical advection follows the seasonality in upwelling. Similarly, the in-mixing term depends on the latitudinal ozone gradient, which seasonality can be affected by upwelling within the tropics. Moreover, as ozone production due to photochemistry and in-mixing along a tropically ascending trajectory both appear weighted with the inverse upwelling velocity (see Eq. 4), a seasonally varying upwelling implies a seasonality in in-mixing of ozone, even if the in-mixing rates were constant throughout the year (result not shown). 
Two examples may further illustrate the implications of these results. First, at levels above the TTL (i.e., above about $\sim 420 \mathrm{~K}$ ), the seasonality of horizontal in-mixing may be neglected to leading order and the amplitude of the annual cycle in tropical upwelling can be estimated from the amplitude in the ozone tendency (divided by a constant ozone background gradient). Second, for calculating tropical ozone profiles (e.g., in photochemical box models), both photochemical production and in-mixing turn out to be essential in the calculation, and about $50 \%$ of summertime ozone in the TTL and at levels above (up to $\sim 20 \mathrm{~km}$ ) is of extra-tropical origin.

\section{Conclusions}

In this paper we reconcile the apparently contrasting views in the literature regarding the seasonality of ozone in the tropical lower stratosphere and its links to tropical upwelling and horizontal in-mixing. By comparing results from a chemistry-climate model and from a one-dimensional Lagrangian transport model, we find that the Eulerian and Lagrangian approaches are consistent and describe different aspects of the ozone transport near the tropical tropopause. Both models show that vertical advection is the main forcing of the tropical mean annual cycle in the lower stratosphere at levels with strong ozone vertical gradients. Additionally, large summertime horizontal in-mixing due to the Asian monsoon circulation is observed in both models near the tropopause. The Lagrangian calculations show that a high fraction of ozone in the TTL and lower stratosphere during summer originates in middle latitudes, and this information cannot be derived from Eulerian budgets. Thus, while the Eulerian and Lagrangian perspectives are consistent, they provide complementary information on transport processes.

Acknowledgements. The authors are thankful to Doug Kinnison for providing the WACCM simulation output. The authors also acknowledge stimulating conversations with Stephan Fueglistaler and Markus Rex. This work was partially supported under the NASA Aura Science Program. The National Center for Atmospheric Research is operated by the University Corporation for Atmospheric Research, under sponsorship of the National Science Foundation. M. Abalos acknowledges Grant BES-2009-013082 and Project CGL2012-34997 of the Spanish Government for funding and NCAR for hosting her visits.

Edited by: W. Lahoz

\section{References}

Abalos, M., Randel, W. J., and Serrano, E.: Variability in upwelling across the tropical tropopause and correlations with tracers in the lower stratosphere, Atmos. Chem. Phys., 12, 11505-11517, doi:10.5194/acp-12-11505-2012, 2012.

Abalos, M., Randel, W. J., Kinnison, D. E., and Serrano, E.: Quantifying tracer transport in the tropical lower stratosphere using WACCM, Atmos. Chem. Phys., 13, 10591-10607, doi:10.5194/acp-13-10591-2013, 2013.

Abalos, M., Randel, W. J., Kinnison, D. E., and Serrano, E.: Quantifying tracer transport in the tropical lower stratosphere using WACCM, Atmos. Chem. Phys. Discuss., 13, 13245-13283, doi:10.5194/acpd-13-13245-2013, 2013.

Andrews, D. G., Holton, J. R., and Leovy, C. B.: Middle atmosphere dynamics, Academic Press, Orlando, Florida, 489 pp., 1987.

Avallone, L. M. and Prather, M. J.: Photochemical evolution of ozone in the lower tropical stratosphere, J. Geophys. Res., 101, 1457-1461, 1996.

Fueglistaler, S., Dessler, A. E., Dunkerton, T. J., Folkins, I., Fu, Q. and Mote, P. W.: Tropical tropopause layer, Rev. Geophys., 47, RG1004, doi:10.1029/2008RG000267, 2009.

Garcia R. R., Marsh, D. R., Kinnison, D. E., Boville, B. A., and Sassi, F.: Simulation of secular trends in the middle atmosphere, J. Geophys. Res., 112, 1950-2003, D09301, doi:10.1029/2006JD007485, 2007.

Grooß, J.-U. and Russell III, J. M.: Technical note: A stratospheric climatology for $\mathrm{O}_{3}, \mathrm{H}_{2} \mathrm{O}, \mathrm{CH}_{4}, \mathrm{NO}_{\mathrm{x}}, \mathrm{HCl}$ and $\mathrm{HF}$ derived from HALOE measurements, Atmos. Chem. Phys., 5, 2797-2807, doi:10.5194/acp-5-2797-2005, 2005.

Konopka, P., Grooß, J.-U., Ploeger, F., and Müller, R.: Annual cycle of horizontal in-mixing into the lower tropical stratosphere, J. Geophys. Res., 114, D19111, doi:10.1029/2009JD011955, 2009.

Konopka, P., Grooß, J.-U., Günther, G., Ploeger, F., Pommrich, R., Müller, R. and Livesey, N.: Annual cycle of ozone at and above the tropical tropopause: observations versus simulations with the Chemical Lagrangian Model of the Stratosphere (CLaMS), Atmos. Chem. Phys., 10, 121-132, doi:10.5194/acp-10-121-2010, 2010.

McKenna, D. S., Konopka, P., Grooß, J.-U., Günther, G., Müller, R., Spang, R., Offermann, D., and Orsolini, Y.: A new Chemical Lagrangian Model of the Stratosphere (CLaMS): 1. Formulation of advection and mixing, J. Geophys. Res., 107, 4309, doi:10.1029/2000JD000114, 2002.

Ploeger, F., Konopka, P., Müller, R., Fueglistaler, S., Schmidt, T. Manners, J. C., Grooß, J.-U., Günther, G., Forster, P. M., and Riese, M.: Horizontal transport affecting trace gas seasonality in the Tropical Tropopause Layer (TTL), J. Geophys. Res., 117, D09303, doi:10.1029/2011JD017267, 2012.

Randel, W. J., Park, M., Wu, F., and Livesey, N.: A Large annual cycle in ozone above the tropical tropopause linked to the Brewer-Dobson circulation, J. Atmos. Sci., 64, 4479-4488, doi:10.1175/2007JAS2409.1, 2007. 